\title{
Early Access to Vocational Rehabilitation for Inpatients with Spinal Cord Injury: A Qualitative Study of Patients' Perceptions
}

\author{
Kumaran Ramakrishnan, MD, ${ }^{1}$ Deborah Johnston, MBMSc, ${ }^{1}$ Belinda Garth, $\mathrm{PhD},{ }^{2}$ \\ Gregory Murphy, PhD, ${ }^{3}$ James Middleton, $\mathrm{PhD},{ }^{1}$ and Ian Cameron, $\mathrm{PhD}^{1}$
}

${ }^{1}$ John Walsh Centre for Rehabilitation Research, Sydney Medical School Northern, The University of Sydney, Kolling Institute of Medical Research, Royal North Shore Hospital, St. Leonards, NSW, Australia; ${ }^{2}$ Southern GP Training Ltd, Churchill, Victoria, Australia, and Department of General Practice, The University of Melbourne, Australia; ${ }^{3}$ Latrobe University, Australia

\begin{abstract}
Background: A pilot early-intervention vocational rehabilitation program was conducted in Sydney, Australia, over a 2-year period. It was postulated that the early provision of integrated vocational rehabilitation services in the hospital settings for newly injured individuals would be well received and result in better employment and psychosocial health outcomes. Objective: The objective of this qualitative inquiry was to examine the perspectives of program participants who had completed the intervention about the timeliness, perceived value, and critical elements of the early intervention. Methods: A convenience sample of participants was selected by accessibility; participants were interviewed individually after discharge using a semi-structured approach. Transcripts of the interviews were created via audio recordings; interviews were transcribed verbatim, and the contents were analyzed thematically. Results: Thirteen participants aged from 19 to 60 years with varying levels of impairment and vocational backgrounds were interviewed from 7 to 21 months post injury. Overall, the early introduction of vocational rehabilitation services was well received and viewed positively. Emerging themes include sense of direction and distraction, advocacy, and support, with "hope" (early after injury) emerging as the overarching theme. Criticisms voiced about the program were that it was offered too early in the intensive care unit and there were competing interests and information overload in the early recovery phase. Conclusions: Vocational rehabilitation provided during inpatient rehabilitation appears appropriate, important, and valuable from patients' perspective. Early engagement results in feelings of hope and encourages patients to see the possibility of returning to work or education very early after injury, and it allows rehabilitation to be directed accordingly. Key words: early intervention, employment, return to work, spinal cord injury, vocational rehabilitation
\end{abstract}

$\mathrm{I}$ ndividuals with spinal cord injury (SCI) consistently rank participation in employment and economic self-sufficiency as being of great importance and priority. ${ }^{1,2}$ Gainful employment for persons with SCI has not only been associated with enhanced quality of life and subjective well being, ${ }^{3}$ but has also been found to be inversely related with risk of mortality. ${ }^{4}$ However, many vocational outcomes such as employment rates and earnings remain suboptimal in this population. ${ }^{5,6}$

Despite the known importance of employment for individuals with SCI, there is a lack of research into the effectiveness of interventions

Corresponding author: Kumaran Ramakrishnan, MD, John Walsh Centre for Rehabilitation Research, Sydney Medical School Northern, The University of Sydney, Kolling Institute of Medical Research, Royal North Shore Hospital, St. Leonards NSW, 2065 Australia; phone: +6 140-523-6211; e-mail: kumaran.ramakrishnan@sydney.edu.au aimed at improving employment outcomes for this population, ${ }^{7}$ with only one randomized controlled trial of vocational intervention among individuals with SCI to date. ${ }^{8}$ This trial found that an outpatient individual placement and support model of vocational rehabilitation (VR) for American Veterans with chronic SCI was more likely to result in competitive employment at 1 and 2 years compared with usual treatment. ${ }^{8}$ It was postulated that even better outcomes might be achieved with VR if it were offered sooner after injury, before social disenfranchisement and reliance on disability benefits become more ingrained.
Top Spinal Cord Inj Rehabil 2016;22(3):183-191

(C) 2016 Thomas Land Publishers, Inc.

www.thomasland.com

doi: 10.1310/sci2203-183 
Internationally, including in Australia, VR is traditionally not provided until after the completion of inpatient rehabilitation in spinal units where services are primarily focused on physical rehabilitation..$^{9,10}$ Where vocational services are available, they are typically delivered after the patient is discharged from the hospital with referral to a community provider. ${ }^{10}$ At the time of discharge, many individuals have preconceived notions of their work ability as employment decisions are often made early during the inpatient stay and are influenced by factors such as self-confidence, perceptions of physical capacity to resume work, uncertainty about job options, and employer expectations. ${ }^{11}$ It has been previously recommended that integration of VR services in the context of the SCI medical team can help facilitate employment outcomes. ${ }^{12}$

To address the suboptimal employment outcomes of individuals with SCI in Australia, ${ }^{13}$ a pilot early intervention VR program, called InVoc, was carried out in the spinal units across the state of New South Wales (NSW), Australia. The primary objective of this early intervention trial was to improve employment outcomes (to be measured prospectively at 1 and 2 years). It was postulated that early provision of integrated VR services in the hospital setting for newly injured individuals with SCI would result in better employment and psychosocial health outcomes. This novel model of care and its core components and some preliminary findings have been described elsewhere. ${ }^{14}$

At the time of this trial, there was uncertainty concerning how individuals with a newly acquired SCI would view the prospect of exploring work or study options at such an early stage after injury (less than 6 months) when hope for physical recovery tends to predominate. ${ }^{15}$ It was also unclear how reluctant and apprehensive the health professionals would be with initiating discussions with patients about work or study at this early stage. It is hard to specify when individuals will have adjusted to their SCI, with little evidence to support claims that it may take at least 2 years to recover from the physical and psychological shock associated with SCI. ${ }^{16}$

Therefore a qualitative evaluation was conducted to explore the experiences and perceptions of inpatients with SCI, service providers, and rehabilitation team members about the program timeliness and their opinions about the most influential and valuable elements of the program. In this article, we report the patients' perspectives with a focus on the timeliness and appropriateness of VR services provided during acute inpatient and rehabilitation hospital stay.

\section{Methods}

All individuals above the age of 16 years with acquired SCI (except due to malignancy and neurodegenerative disorders) admitted to the 3 spinal units in the state of NSW, Australia, during a 2-year period (June 1, 2011 to May 30, 2013) were invited to participate in the InVoc program. Initial contact with the newly injured patient was made by a vocational consultant (within 6 months from the time of injury) after the rehabilitation team had reached agreement via case conference that the patient was well enough (medically and psychologically) to participate.

The vocational consultant (VC) then worked in partnership with the person with SCI to undertake comprehensive VR assessments and identify barriers, solutions, and initiatives to facilitate a return to work or study, thus supporting that person to develop and implement an individualized integrated rehabilitation plan while still in hospital. The VC also worked collaboratively with members of the spinal unit clinical teams, attending case conferences as well as contributing to medical records, to ensure the program was well integrated into the overall inpatient rehabilitation program.

Upon completion of the pilot program and discharge from the hospital settings, a qualitative evaluation was carried out by a team of researchers to explore the perceptions and experiences of the program participants. This team comprised experts in SCI rehabilitation, vocational counseling, psychology, and qualitative research. The participants of this qualitative inquiry were recruited by accessibility (convenience sampling). Any program participants who had a follow-up medical appointment after discharge from 1 of the 3 participating spinal units were contacted 
by telephone and invited to participate in an interview either in person or by phone. Ethical approval to conduct the interviews was granted by a local human research ethics committee, with all participants providing informed consent.

The recruitment and subsequent interviews were carried out by a research team member who had no involvement in patient care, as this could potentially inhibit frank discussions if patients believed that their responses would affect their treatment. However due to practical reasons, the setting of most of the interviews was in the hospital outpatient department. Three participants completed their interviews by phone, and 10 interviews were conducted face to face.

The interviews were semi-structured, and interviewers predominantly used the same target questions (examples of which can be found in Table 1) to initiate discussion with further probing as required. Examples of questions used to ascertain value and critical elements of the program include: "What do you think was the most and least helpful part of the service? What was useful and of benefit to you? Any positive and/or negative aspects of the service delivery? Any feedback about what you thought about the program? Any general comments? Transcripts of the interviews were created via audio recordings; interviews were transcribed verbatim, with additional notes created by interviewer.

The data analysis was conducted by another member of the research team who is experienced in qualitative research. The analysis was done concurrent with data collection. A qualitative description approach ${ }^{17}$ was chosen as the research methodology as it allowed for a straightforward description of the phenomenon under focus. Thematic analysis (within a realist/essentialist paradigm) was used to analyze the data inductively and deductively. ${ }^{18}$ This relatively surface level, thematic analysis of qualitative data was aimed to produce findings that can be applied rapidly to practice in health services research as well as lead to new research questions that can be explored in greater depth at a later stage. ${ }^{19}$ Emerging codes and themes were presented to the other research team members for comment throughout the analysis process to enable cross-checking and to achieve consensus, particularly about data saturation. The consensus that was achieved for saturation was in relation to the primary research question of timeliness of intervention in the hospital settings.

\section{Results}

During the 2 years that the InVoc pilot was conducted, 168 of 328 patients admitted to the 3 spinal units in the state of NSW, Australia, participated in the program. The majority of those not participating were retired aged pensioners with no vocational and/or study goals, with the remainder either having medical or psychological issues deemed unsuitable for VR by the treating team or declining participation. The sampling of participants for this qualitative inquiry began in early October 2013 and ended in April 2014, with a total of 13 participants of varying levels and severity of injury as well as occupational backgrounds (pre and post injury) completing interviews (see Table 1).

All but one of the participants were male and ranged in age from 19 to 60 years at the time of injury. Time since injury ranged from 7 to 21 months, averaging around 14 months. Almost all the participants (12 out of 13) were working at the time of injury, whereas at the time of interview 4 were employed and 5 were engaged in study or retraining. The themes that emerged from the analysis were categorized into 2 key areas: (1) timeliness and (2) value and critical elements of the program.

\section{Timeliness of early VR intervention}

Participant responses to the timeliness of the InVoc intervention are presented in Table 1 . The responses are only slightly edited to maintain anonymity, but otherwise they are presented in their original form with the corresponding cue or question that preceded them for context. They are organized in a descending order of (perceived) positiveness of opinions to highlight the contrast in perspectives. The key biographical details are presented alongside in Table 1.

The majority of the participants ( 8 of 13) were unequivocal in their support of the early 
Table 1. Participants' perspectives on timeliness of intervention presented in descending order of (perceived) positiveness along with key demographic details

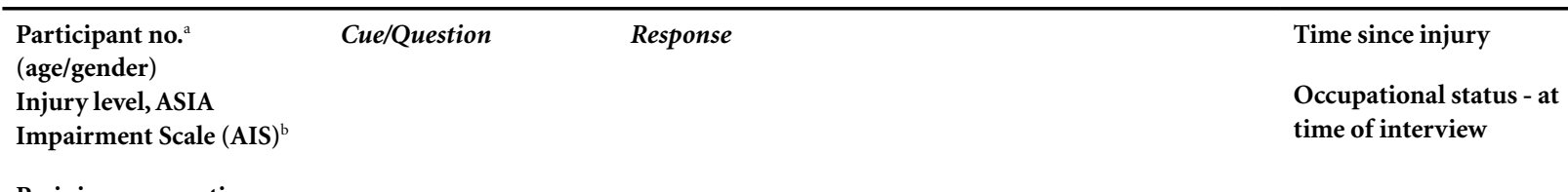

Preinjury occupation

\begin{tabular}{|c|c|c|c|}
\hline $\begin{array}{l}\text { P2 (57/Male) } \\
\text { C7, AIS D } \\
\text { Unemployed: On disability } \\
\text { pension }\end{array}$ & $\begin{array}{l}\text {--did you think that } \\
\text { any of the services were } \\
\text { offered too early? }\end{array}$ & $\begin{array}{l}\text { No. No, I don't think so. I think once you come out of ICU, } \\
\text { I think it's wonderful that there we had more options to, sort } \\
\text { of, you know, broaden our horizons concerning giving us } \\
\text { direction. }\end{array}$ & $\begin{array}{l}\text { Unemployed: In } \\
\text { rehabilitation program } \\
\text { to walk }\end{array}$ \\
\hline $\begin{array}{l}\text { P7 (40/Male) } \\
\text { T10, AIS D } \\
\text { Employed: Hospital lab } \\
\text { technician }\end{array}$ & $\begin{array}{l}\text { So, thinking about the } \\
\text { timing, so when you } \\
\text { were first approached, } \\
\text { how did you feel about } \\
\text { that; did you think } \\
\text { anything was too soon? }\end{array}$ & $\begin{array}{l}\text { I don't think was too soon. I don't think was too soon, I } \\
\text { think actually was the right - I think was the right time, } \\
\text { because, I-I - mine was not for - my injury was not caused } \\
\text { by a trauma, so was something that - well, even if was from } \\
\text { a trauma anyway, it's - it's an unexpected situation. And, } \\
\text { being an unexpected situation, you have to deal with the } \\
\text { emotion and to deal - and, try to organize your life from one } \\
\text { day to the other in a totally different way... }\end{array}$ & $\begin{array}{l}21 \text { months } \\
\text { Employed: Sterilizing } \\
\text { technician }\end{array}$ \\
\hline $\begin{array}{l}\text { P13 (23/Male) } \\
\text { C5, AIS B } \\
\text { Employed: Physiotherapist }\end{array}$ & $\begin{array}{l}\text { How do you feel about } \\
\text { the timing? Did you feel } \\
\text { like anything there was } \\
\text { offered too soon? }\end{array}$ & $\begin{array}{l}\text { Not-not particularly. I didn't feel that was a big issue. It } \\
\text { was probably-probably the right timing. I was approached, } \\
\text { probably I think, maybe first two weeks, I - I think. No I } \\
\text { didn't-didn't feel like it was too early, but I think that was } \\
\text { the - the trial whether or not having early intervention was } \\
\text { a-was a - had any impact. }\end{array}$ & $\begin{array}{l}16 \text { months } \\
\text { Unemployed: University } \\
\text { student }\end{array}$ \\
\hline $\begin{array}{l}\text { P12 (33/Male) } \\
\text { C4, AIS A } \\
\text { Employed: Brick laborer }\end{array}$ & $\begin{array}{l}\text { Did you think anything } \\
\text { was approached too early } \\
\text { for you? }\end{array}$ & $\begin{array}{l}\text { No, no, not at all. I think-I think the earlier the better } \\
\text { because the more time that you leave it, the less likely I } \\
\text { probably would've been to- to get interested in it, you know. }\end{array}$ & $\begin{array}{l}15 \text { months } \\
\text { Unemployed: } \mathrm{TAFE}^{\mathrm{c}} \\
\text { student }\end{array}$ \\
\hline $\begin{array}{l}\text { P1 (19/Female) } \\
\text { L4, AIS D } \\
\text { Employed: Motor } \\
\text { mechanic apprentice }\end{array}$ & $\begin{array}{l}\text { Do you think there was } \\
\text { anything that you felt } \\
\text { was too early? }\end{array}$ & $\begin{array}{l}\text { No. Not really. I- I was keen to go back to work, kind } \\
\text { of thing, and [staff name] kind of helped me boost my } \\
\text { confidence even more to go back and, yeah. She helped me } \\
\text { a lot.t }\end{array}$ & $\begin{array}{l}9 \text { months } \\
\text { Unemployed: Job } \\
\text { seeking }\end{array}$ \\
\hline $\begin{array}{l}\text { P5 (43/Male) } \\
\text { T12, AIS D } \\
\text { Employed: Machine } \\
\text { maintenance worker }\end{array}$ & $\begin{array}{l}\text { Do you think anything } \\
\text { for you is too early, too } \\
\text { soon? }\end{array}$ & $\begin{array}{l}\text { Because I wasn't here that long, only in the rehab for two, } \\
\text { two, two months and } 10 \text { days yeah, not that long, so I think } \\
\text { the, the program start early is good for me, because I wasn't } \\
\text { that long here, so I really prepare myself to facing my real, } \\
\text { what say real job when I go out. }\end{array}$ & $\begin{array}{l}\text { Employed: Machine } \\
\text { maintenance worker }\end{array}$ \\
\hline $\begin{array}{l}\text { P8 (57/Male) } \\
\text { C4 AIS A }\end{array}$ & $\begin{array}{l}\text { Do you think anything } \\
\text { was too soon? So a bit } \\
\text { too early for you? }\end{array}$ & $\begin{array}{l}\text { I don't think so, but it's - it depends on my conditions, my } \\
\text { health conditions. But I'm willing, [inaudible] more prepare, } \\
\text { back to my job. }\end{array}$ & $\begin{array}{l}\text { Employed: Casual } \\
\text { journalist }\end{array}$ \\
\hline $\begin{array}{l}\text { Employed: Church } \\
\text { minister }\end{array}$ & $\begin{array}{l}\text { Did you feel like } \\
\text { anything was too soon? }\end{array}$ & $\begin{array}{l}\text { No not ... not really no. No. I suppose ... at the beginning } \\
\text { when I was still in hospital that they introduced themselves } \\
\text { within, I don't know, first two weeks I thought was a bit } \\
\text { soon. But it's hard to tell like some people want to know that } \\
\text { there's help. Well I wasn't really thinking about that at the } \\
\text { time. I just thought it was one extra thing that I didn't need. }\end{array}$ & $\begin{array}{l}\text { Unemployed: In } \\
\text { rehabilitation }\end{array}$ \\
\hline $\begin{array}{l}\text { P11 (53/Male) } \\
\text { T12, AIS B }\end{array}$ & $\begin{array}{l}\text { What did you think } \\
\text { about the timing? Did } \\
\text { you think anything was } \\
\text { too soon? }\end{array}$ & $\begin{array}{l}\text { Well, I'm not really sure, but at that time I'm still not- } \\
\text { motivated to be in doing something and right now, with all } \\
\text { these things happening, my timeframe is just getting shorter } \\
\text { and shorter, so I need to adjust if I would be going to work or } \\
\text { going to study. }\end{array}$ & $\begin{array}{l}12 \text { months } \\
\text { Unemployed: Enrolled } \\
\text { in TAFE } \text { (not } \\
\text { commenced yet) }\end{array}$ \\
\hline
\end{tabular}


Table 1. Participants' perspectives on timeliness of intervention presented in descending order of (perceived) positiveness along with key demographic details (CONT.)

\begin{tabular}{|c|c|c|c|}
\hline \multirow[t]{2}{*}{ Employed: Brick laborer } & $\begin{array}{l}\text { What did you think } \\
\text { about the timing? Did } \\
\text { you think anything was } \\
\text { too soon? }\end{array}$ & $\begin{array}{l}\text { No, when I came to rehab, I think that's kind of the time that } \\
\text { you want to kind of get involved with people .... }\end{array}$ & \multirow[t]{2}{*}{$\begin{array}{l}\text { Employed: Working } \\
\text { with wheelchair sport }\end{array}$} \\
\hline & $\begin{array}{l}\text { And then when you } \\
\text { transferred over and } \\
\text { then were given this--, } \\
\text { do you feel like that was } \\
\text { still a bit too early? }\end{array}$ & $\begin{array}{l}\text { Yeah, maybe a bit early. Because I first, kind of, dealt with } \\
\text { them at Royal North Shore. Yeah. Yeah. Which was just } \\
\text { a bit too early. Plus all the other information that they } \\
\text { bombard you with, like, bloody funding bodies and all the } \\
\text { rest of it. You know, the long--you know, and you're just } \\
\text { really focusing on just getting better. }\end{array}$ & \\
\hline P6 (24/Male) & So you felt like that was & Yeah, a bit too invasive at that point. It was, yeah, I'm trying & 14 months \\
\hline T8, AIS A & a bit too soon? & $\begin{array}{l}\text { to concentrate on getting well rather than thinking of a new } \\
\text { career. }\end{array}$ & \multirow{2}{*}{$\begin{array}{l}\text { Unemployed: University } \\
\text { student }\end{array}$} \\
\hline Employed: Lumber trade & $\begin{array}{l}\text { And then when it was } \\
\text { brought up again after } \\
\text { you'd been discharged - } \\
\text { you transferred to rehab }\end{array}$ & Yeah, that was a better time, yeah. & \\
\hline $\begin{array}{l}\text { P10 (60/Male) } \\
\text { C3, AIS C }\end{array}$ & $\begin{array}{l}\text { Do you think anything } \\
\text { was too soon? }\end{array}$ & I think it was too soon & 15 months \\
\hline Employed: Laborer & $M m \ldots$ & $\begin{array}{l}\text { like I say, I'm having trouble just moving around. I can't see } \\
\text { me doing, returning to work and doing anything useful. }\end{array}$ & $\begin{array}{l}\text { Unemployed: Not } \\
\text { looking for work }\end{array}$ \\
\hline $\begin{array}{l}\text { P9 (24/Male) } \\
\text { T6, AIS A }\end{array}$ & \multirow{2}{*}{$\begin{array}{l}\text { What did you think } \\
\text { about the timing? Did } \\
\text { you think anything was } \\
\text { too soon? }\end{array}$} & $\begin{array}{l}\text { Very soon. Very, very soon. Too soon in my opinion. You } \\
\text { know, you need time to process what's happened to you. }\end{array}$ & 19 months \\
\hline $\begin{array}{l}\text { Employed: Marine } \\
\text { technician }\end{array}$ & & $\begin{array}{l}\text { When, and I believe her name was [staff name], now I } \\
\text { don't want to - I don't want to like put her name down } \\
\text { or anything, but you know, I just wasn't - me personally I } \\
\text { wasn't ready to discuss my future. I didn't even know what } \\
\text { was happening with me medically, let alone, you know. I } \\
\text { really think people need to be out of the acute stage before } \\
\text { they're interviewed to sort of get like, I honestly had no } \\
\text { idea whether I'd even get movement in my hands back or } \\
\text { anything like that. Last thing I wanted to think about right } \\
\text { then was what TAFE' course am I going to do... }\end{array}$ & $\begin{array}{l}\text { Unemployed: Advanced } \\
\text { diploma student }\end{array}$ \\
\hline
\end{tabular}

\footnotetext{
a Participant number corresponds to the timing of interview, with P1 being the first to be interviewed and P13, the last in the sampling.

${ }^{\mathrm{b}}$ Injury level and the neurological severity of spinal cord injury were classified according to the International Standards for Neurological Classification of Spinal Cord Injury as published by the American Spinal Injury Association (ASIA).

${ }^{\mathrm{c}}$ TAFE $=$ Technical and Further Education institution.

${ }^{\mathrm{d}}$ Royal North Shore $=$ major acute care hospital based in Sydney.
}

introduction of VR services. Two participants (P3 and P11) seemed rather uncertain about the timing, while 3 participants felt it was offered "too early" in the acute setting (particularly the intensive care unit) but agreed that the rehabilitation ward setting was more appropriate.

The importance of early intervention in creating a positive expectation and motivation in some participants was highlighted by comments shown in Table 1 such as "...the earlier the better because the more time that you leave it, the less likely I probably would've been to, to get interested in it..." (P12) and "...helped me boost my confidence even more to go back...” (P1). Conversely, other comments such as "...you're just really focusing on just getting better" (P4), “...I'm trying to concentrate on getting well rather than thinking of a new career" (P6), and "...you need time to process what's happened to you" (P9) highlighted that for some individuals InVoc may be offered too early (ie, in the acute phase within several weeks of injury, rather than a little later during rehabilitation), when a person is still coming to terms with his or her injury. 


\section{Value and critical elements of early intervention VR program}

Themes that emerged from the data regarding the value of the service include hope (early after injury), a sense of direction with options, and advocacy and support. The importance of hope was voiced rather emphatically by one of the participants as illustrated below.

You know, so the fact that we have there, somebody that says, yes, if you want to go back to work we can help you; yes, you can go back to work, because there is a program; yes, there is a chance that you can go back. I think that was the hope that actually even helped me to get better... (P7)

I couldn't imagine myself being 40 at the time, or not even 40, that I couldn't, you know, to think I was out of the work force. I - I couldn't imagine myself at that age to stay home doing nothing, you know... (P7)

The importance of hope (being future oriented) on psychological health and well being is underpinned by comments such as "...put in better frame of mind...clearer future...some solid goals we can work towards...big part to play in managing someone's mental health" (P13) and “... opened a few more doors, like I was adamant I wasn't going to be driving, I didn't want to drive, but then, you know, obviously TAFE [Technical and Further Education institution] schedules and that, I went, all right, I probably should get my license. So, you know, it definitely helped me out and make some decisions and get me on the right foot to getting back to life really..." (P9).

Not only a sense of direction, but also distraction and having choices seemed important for participants to feel empowered, and were reflected in comments such as "...gave me options...good options...other directions to look into...” (P2), “... the more options you've got while you're in places like this, the better...” (P4), “...it was good to keep me mind on something other than what was going on..." (P12), and "...the really helpful things were providing me with details of, you know, the various support services at uni and - and that, you know, studying was a possibility" (P13).

Advocacy and support were also crucial from the patients' perspective, and one participant expressed the role of the service provider as a "referee."

I think that the fact that with an outsider there, telling them okay, this person needs help, I think that actually that puts social pressure on the institutions to take us back and to look after us, because it's almost like involve almost, well, it's almost like a referee, that he say, okay guys, here, there is somebody from outside of the institution looking. And, then the institution wants to look great to the outside world, do you know what I mean? (P7)

Support and advocacy can also happen in the context of the multidisciplinary rehabilitation team:

And she actually told the physio and that to, like, build weights, kind of thing, like as if I was picking up a wheel off the ground. And that's--by the end of, like, the last week that I was here I was actually doing that, like, I was starting to lift up a wheel off the ground with a few weights on it to make it as heavy as a wheel. And like, yeah, well, after I knew that I could do that, my self-esteem kind of just went straight through-back through the roof and I was just, like, "Yeah, man, I'm back on track, like." (P1)

Other examples of support and advocacy, include participants expressing that "...and, so and, the fact that I had a professional there saying that's all right, we will do the best we can to help you and there is many things that we can do for you. We can give you training, we can send you for education, we can negotiate with your workforce..." (P7) and "I mean, she did a lot with my boss too and - and yeah, it just made so many things easier for me, like, I didn't have to worry about making a phone call because like, yeah, she'd do it for me, kind of thing. And it helped, like, when you're in rehab, the last thing you want to do is sit on the phone all day to people and explain the situation" (P1).

The critical elements of the service can be said to be attributed to the characteristics of the service providers (VCs) being caring and compassionate, efficient and innovative, as highlighted below.

I think the compassion and care that was shown to me and the good direction that I was given in making choices and funneling down my thought processes....(P2)

And, being an unexpected situation, you have to deal with the emotion and to deal - and, try to organize your life from one day to the other in a totally different way, so, it was for me, in my personal point of view, to have [staff name] there and she was so reassuring and she was so caring and so pleasant, and there to tell me, okay, I - I'm not alone....(P7)

I was keen to go back to work, kind of thing, and [staff name] kind of helped me boost my confidence even more to go back and, yeah. She helped me a lot.... She got me on a roller board as well, like, that you slide underneath a car, and I didn't--to be truthful, I didn't actually think I would be able to do it, 
but [staff name] kind of, she--I don't know, she just boosted my confidence with everything and helped me get back to the mind-frame that I would be going back to work, kind of thing, and, yeah, helped me a lot....(P1)

Ah, just that any time I had any questions she was just straight, straight onto it, she would do the research, call up unis or TAFE institutes and yeah, print off all the information, email me, send them out in posts. She was, yeah, she was great, yeah, very efficient, yeah... .(P6)

The areas for improvement that were identified include the need for better communication to patients about the role of VCs and the preference for one-on-one sessions with the VCs (not shared sessions with other patients). For patients transitioning to work/study at a later stage, the ability to reconnect and access support for this transition was also identified as important. There was also the issue of competing interests and feeling overwhelmed with information overload early after injury as highlighted by one participant below.

\begin{abstract}
...in acute it was very rushed and you know, lots of time commitments, so I think I - when I saw them there was - they were popping in and out and sometimes had information for you. But I can definitely see how having lots of competing interests with lots of different health professionals doesn't help, and not having really the - the idea of what was happening or what was going on, didn't really help.... (P13)
\end{abstract}

\section{Discussion}

Overall, the early introduction of VR services appears appropriate, important, and valuable from patients' perspective. It seems reasonable to offer vocational interventions in the context of inpatient multidisciplinary rehabilitation phase and setting. However, the need for sensitivity and collective wisdom of the multidisciplinary team to ascertain the "readiness" of the patient to discuss vocation must be recognized. Although this was the practice in this pilot intervention, the reported experiences of some participants suggest that the amount, depth, and type of information being presented, as well as the timing, at this very early stage is important. A possibility would be to start with a brief introduction of the service and encouragement of the patients to see the possibility of their returning to some form of work and/or study in the future, and then allowing the patients control over when they feel ready to take that discussion to the next level and engage further with the VC.

Hope (early after injury) seems to be the overarching theme in this study, and this is congruent with the prevailing literature. Lohne and Severinsson ${ }^{15}$ highlighted the experience of hope during the first months after SCI and have recommended fostering hope to enable recently injured patients to look beyond the immediate situation and direct their energies appropriately. This reinforces the value of initiating discussions about work or study at an early stage after an injury, maintaining hope with future orientation and vocational identity with a sense of direction and having options, and in some cases providing distraction from current problems, particularly at a distressing and very uncertain time soon after injury.

A phenomenological hermeneutic narrative approach among 12 traumatic patients with SCI observed in a rehabilitation unit noted that the patients' perception of vulnerability varied and strength was mobilized as a response to the vulnerability to overcome the imbalance between demands and resources. ${ }^{20}$ This parallels the experience of some of this study's participants (eg, P1 in describing the characteristics of VCs). This also indirectly highlights the potential for vocational goals to guide and direct overall rehabilitation goals in a very meaningful way.

VCs were also seen as advocates for the patients, specifically with preinjury employers and education providers, with some participants voicing strong doubts that they would be able to navigate return to these environments without a third party's help, support, and assistance. In Australia, these forms of assistance are traditionally provided by community-based VR service providers, however, having VCs with specific vocation-related knowledge and skills as an integral part of rehabilitation team makes it possible to maintain a focus on existing employment. Inpatient service provision has the potential to increase the likelihood of returning to preinjury employment and avoiding retraining and job seeking thus facilitating an accelerated return to employment or education. 


\section{Limitations}

This qualitative evaluation used convenience sampling of registry of medical appointments at 1 of the 3 participating spinal units to recruit participants due to limitations in time, logistics, and resources. Despite this, there was a wide variability in key characteristics (including age, severity of injury, and employment status) that can potentially offer varying viewpoints for the primary research question, such as that obtained from criterion sampling. ${ }^{21}$ We acknowledge that given the convenience sampling, we are not able to analyze variation in themes by key participant characteristics. This evaluation also did not probe participants deeper than surface levels (eg, using in depth, repeated interviews) due to practical limitations, however the relatively surface level, thematic analysis of qualitative data was aimed to produce findings that can be applied rapidly to practice in health services research and lead to new research questions that can be explored in greater depth in the future. ${ }^{19}$ Our qualitative description approach obviously limits deeper and fuller understanding of events and experiences, which are best explored within other paradigms and methodologies.

\section{Implications for future research}

Future studies are required to understand from the patients' perspective (as well as from the perspectives of persons in the patients' lives, such as caregivers or loved ones) how the breaking of the bad news in terms of prognosis for significant motor recovery following SCI intersected with discussions about return to work or study at such an early stage after injury. It is also worth exploring what constitutes effective communication particularly when issues about prognosis and the future are discussed. Additionally, exploration into the personal and contextual factors that facilitate or hinder discussion about return to work or study in the early postinjury period is required, as well as what constitutes "readiness" and how this can be ascertained by the rehabilitation team.

\section{Conclusion}

The inpatient provision of VR services within Australian SCI units is perceived by program participants as being appropriate, effective, and valuable. Early engagement with VR services results in feelings of hope and can assist patients to engage with the possibility of returning to work and/or education very early following injury.

\section{REFERENCES}

1. Backman C, Forwell S, Carpenter C, Jongbloed L. Priority issues for British Columbians living with spinal cord injury. Int J Disabil Community Rehabil. 2007;6.

2. Simpson LA, Eng JJ, Hsieh JT, Wolfe, the Spinal Cord Injury Rehabilitation Evidence Research Team DL. The health and life priorities of individuals with spinal cord injury: A systematic review. J Neurotrauma. 2012;29(8):1548-1555.

3. Chapin MH, Holbert D. Employment at closure is associated with enhanced quality of life and subjective well-being for persons with spinal cord injuries. Rehabil Counsel Bull. 2010;54(1):6-14.

4. Krause JS, Saunders LL, Acuna J. Gainful employment and risk of mortality after spinal cord injury: Effects beyond thatofdemographic, injuryand socioeconomic factors. Spinal Cord. 2012;50(10):784-788.

5. Ramakrishnan K, Loh SY, Omar Z. Earnings among people with spinal cord injury. Spinal Cord. 2011;49(9):986-989.

6. OHtomanelli L, Lind LM. Review of critical factors related to employment after spinal cord injury:
Implications for research and vocational services. $J$ Spinal Cord Med. 2009;32(5):503-531.

7. Trenaman LM, Miller WC, Escorpizo R, the SRT. Interventions for improving employment outcomes among individuals with spinal cord injury: A systematic review. Spinal Cord. 2014;52:788-794.

8. Ottomanelli L, Barnett SD, Goetz LL. Effectiveness of supported employment for veterans with spinal cord injury: 2-year results. Arch Phys Med Rehabil. 2014;95(4):784-790.

9. New PW, Townson A, Scivoletto G, et al. International comparison of the organisation of rehabilitation services and systems of care for patients with spinal cord injury. Spinal Cord. 2013;51(1):33-39.

10. King T, Emery R, Warren S, Landis T. A collaborative approach to returning clients to work during the first year after spinal cord injury. Top Spinal Cord Ini Rehabil. 2004;9(4):33-42.

11. Fadyl JK, McPherson KM. Understanding decisions about work after spinal cord injury. J Occup Rehabil. 2010;20(1):69-80. 
12. Cotner B, Nioh E, Trainor J, O'Connor D, Barnett $S$, Ottomanelli L. Facilitators and barriers to employment among veterans with spinal cord injury receiving 12 months of evidence-based supported employment services. Top Spinal Cord Inj Rehabil. 2015;21(1):20-30.

13. Young $A E$, Murphy $G C$. Employment status after spinal cord injury (1992-2005): A review with implications for interpretation, evaluation, further research, and clinical practice. Int J Rehabil Res. 2009;32(1):1-11.

14. Middleton JW, Johnston D, Murphy G, et al. Early access to vocational rehabilitation for spinal cord injury inpatients. J Rehabil Med. 2015;47(7):626631.

15. Lohne V, Severinsson E. Hope during the first months after acute spinal cord injury. J Adv Nursing. 2004;47(3):279-286.
16. Sand $\AA$, Karlberg I, Kreuter M. Spinal cord injured persons' conceptions of hospital care, rehabilitation, and a new life situation. Scand J Occup Ther. 2006;13(3):183-192.

17. Sandelowski M. What's in a name? Qualitative description revisited. Res Nursing Health. 2010;33(1):77-84.

18. Braun V, Clarke V. Using thematic analysis in psychology. Qual Res Psychol. 2006;3(2):77-101.

19. Kelly $M$. The role of theory in qualitative health research. Family Pract. 2010;27(3):285-290.

20. Angel S. Vulnerable, but strong: The spinal cordinjured patient during rehabilitation. Int I Qual Stud Health Well-being. 2010;5(3).

21. Palinkas LA, Horwitz SM, Green CA, Wisdom JP, Duan N, Hoagwood K. Purposeful sampling for qualitative data collection and analysis in mixed method implementation research. Admin Policy Mental Health. 2013;42(5):533-544. 